\title{
Indexical time references and attitude reports
}

\author{
Silvia P. Gennari \\ University of York \\ silvia.gennari@york.ac.uk
}

\begin{abstract}
An indexical tense occurring in intensional domains, as in John believed that Mary is pregnant conveys a mismatch between the content reported and the content intuitively attributable to the believer: The actual belief does not seem to involve an indexical reference to the speech time. Current logicosemantic accounts of this mismatch propose a de re interpretation, e.g., there is a state in the real world, of which John believes something. Following Gennari's (1999a; 2003) account, it is argued that current accounts do not capture multiple instances of belief attributions with indexical tenses and an alternative more flexible account is proposed. Specifically, indexical tenses need not be analyzed de re if the belief reports is considered as an attribution of an implicit belief, rather than an explicit one (Stalnaker 1999). Such attributions are felicitous if there is an inference pragmatically attainable in the common ground that allows the speaker to infer and assert the attributed content. The speaker infers the reported content making extra assumptions normally taken for granted. The account correctly predicts whether a given present or future attitude report is felicitous depending on the availability of the speaker's inference.
\end{abstract}

Keywords: semantics and pragmatics; formal semantics; indexical tenses; attitude reports; philosophy of language

\section{Introduction}

Reference to entities within intensional or belief contexts have since long elicited numerous accounts and discussions in philosophy and semantics. As an illustration, consider Quine's (1960) example of Ralph's beliefs. Ralph glimpsed a guy wearing a brown hat on the beach, which the speaker identifies as Ortcutt, and thinks that the guy is a spy. In this scenario, the speaker can report Ralph's belief as Ralph believes that Ortcutt is a spy, where Ortcutt is said to be interpreted de re, given that Ralph does not represent the guy as Ortcutt. The interpretation would be said to be de dicto if one reports Ralph belief as Ralph believes that the man he saw on the beach is a spy, as this more closely matches Ralph's belief content. Thus, de re interpretations are those where there is a mismatch between the believed content and the reported belief. I will call these characteristic interpretations the content-report mismatch. 
Similar mismatches can be observed for indexical tenses such as present and future tense within intensional contexts: the actual intuitive content of the propositional attitude does not seem to agree with the content reported by the speaker. Consider for example:

(1) Bill believed that Hillary is pregnant.

(2) Bill will believe that Hillary is pregnant.

(3) Bill believed that Hillary will come by train.

In (1), the interval at which Hillary is pregnant may overlap with both Bill's believing time and the speaker's speech time, called the double access reading (Abusch 1991; 1997), as the interval in question encompasses the utterances time and the time at which the belief was held. But, intuitively, Bill's beliefs do not include the present speech time (ST), i.e., a future time from Bill's past perspective. Bill presumably had a belief about Hillary being pregnant at a past interval (overlapping with the time of his belief) and not necessarily at an interval extending into his future. The use of the indexical tense conveys temporal information that does not seem attributable to the believer. Such interpretations have been extensively discussed in the literature (cf. Enç 1987; Smith 1978; Comrie 1985; Altshuler 2016). Similar observations hold for (2), where the embedded sentence may overlap with both the future believing time and the ST. The belief Bill will have in the future will surely represent Hillary as being pregnant at the future time of the belief, and not necessarily at the ST, a past time form Bill's future perspective. Likewise, in (3), the believer seems to have a belief about an event later than his believing time, but the future interval at which Hillary will come is represented as later than the ST. In all cases, the temporal reference to the ST in the reported belief does not coincide with the temporal belief the believer seems to have entertained or will entertain. By analogy with other types of reference, it has been argued that these cases involved de re interpretations about intervals or states.

In what follows, first I outline the de re solution to present under past reports, pointing out some problems within this account. Then, I adopt and extend Gennari's (1999a; 2003) solution, and argue that this account can explain most difficult cases. Although Altshuler's (2016) and Klecha's (2016) accounts, like Gennari's (1999a; 2003) account, does not rely on a de re solution in most cases, they do adopt de re analyses for some difficult cases, making the present tense ambiguous between different interpretations. Moreover, these accounts simply stipulate the right interpretation 
for double access interpretations, but do not provide an explanation for the content-report mismatch intuition, i.e., why it is that the speaker can attribute a belief including the speech time. In the last sections, I extend the account to present embedded under future and future embedded under past.

\section{Previous solutions}

Extant accounts of temporal content-report mismatches (Abusch 1991; 1997; Ogihara 1996) propose that there is a de re interpretation of the embedded tense, parallel to those found with regular NPs. They propose that embedded indexical tenses are represented by a logical existential quantifier outside the intensional domain and denote a state or interval in the utterance context. The embedded tense, rather than being part of the intentional content of the believer, is the speaker's way of referring to the actual external entity the belief is about. In the belief worlds, this entity may be represented differently, as in Quine's example.

The particular implementation of de re readings adopted from the nominal domain is that of Cresswell \& von Stechow (1982). The analysis involves a res, i.e., the actual entity toward which the attitude is held. The object of belief is a structured meaning, a pair consisting of an individual and a property $\langle b, P\rangle$, where $b$ is the res of which the property $P$ is predicated. To guarantee that the individual in the belief worlds is the same as that in the actual world, the account also assumes following Kaplan (1968) and Lewis (1979) that the res is presented to the believer in a certain way via a causal connection (or acquaintance relation). This is captured by postulating a suitable cognitive relation $R$ between the believer and the res presupposed in the context. The truth conditions for de re belief reports are as follows: $a$ believes $P$ of $b$ iff $a$ bears some suitable relation $R$ to $b$ in the actual world $w$ and every belief world $w^{\prime}$ of $a$ satisfies the property of bearing $R$ uniquely to something which has $P$ in $w^{\prime}$. Thus, $R$ picks up $b$ in the actual world, while in the belief worlds, it picks up whoever $a$ is uniquely acquainted with. For the case of Quine's example, the acquaintance relation is a relation $R$ such as $x$ glimpses $y$ on the beach. Then, Ralph believes Ortcutt to be a spy iff Ralph glimpses Ortcutt on the beach in the actual world, and every belief world of Ralph is such that Ralph glimpses someone on the beach who is a spy. This captures the fact that in de re readings, there are different ways of representing the individual Ortcutt. The content of the acquaintance relation gives us the way Ralph represents the individual in the belief worlds (the guy seen 
on the beach), while Ortcutt is the way the speaker refers to him in the actual world.

To apply this analysis to the temporal domain, the object of which an individual has a belief must be a temporal entity - an interval or state -, and the property, a temporal property. Consider the case of (1) repeated below:

\section{(1) Bill believed that Hillary is pregnant.}

Bill may have seen Hillary once and thought she was pregnant, although she may have actually been overeating. In this scenario, Bill is acquainted with the interval of Hillary's having a big belly, and he believes of this interval to be such that Hillary is pregnant in it. The acquaintance relation is as follows: $\mathrm{R}_{3}: \lambda t_{\text {now }} \lambda x \lambda t \lambda w(t$ is the maximal interval overlapping with $t_{\text {now }}$ at which Hillary $(x)$ has a big belly in $w$ ), where $R_{3}$ is a relation between the res interval $t$ and the individual $x$ in $w$ at $t_{\text {now }}$, the believer's now or the belief time. It picks out the maximal interval overlapping with the believer's now at which Hillary has a big belly. Applying Cresswell \& von Stechow's (1982) proposal, (1) is true iff (a) there is a relation $R$ that causally connects the res interval $t$ with Bill at the time of believing $t_{\text {now }}$ in the actual world $w$ and (b) for all Bill's cognitive alternatives, the interval to which Bill is acquainted in his belief worlds has the property of being the interval of Hillary's pregnancy.

Note however that these truth conditions do not necessarily yield an interpretation in which the present ST overlaps with the belief time. As they stand with this particular relation $R_{3}$, they only guarantee that the interval picked out by $R_{3}$ overlaps with the time of the belief. Therefore, additional assumptions are needed to ensure that the interval denoted by the present tense is also the interval picked out by $R$ in the belief worlds, which overlaps with the believing time. Although Abusch's and Ogihara's accounts differ in the mechanisms they assume to arrive at the right interpretation, both accounts propose similar truth conditions. The double access overlapping reading is explained because the truth conditions themselves require that the res state/interval to which the believer is acquainted obtains at the ST. The final representation at the Logical Form and truth conditions for (1) is the following (adapted from Ogihara 1996, 214):

(4) a. LF: [CP Pres ${ }_{2}\left[{ }_{\mathrm{S}}\right.$ Bill Past believe $\mathrm{s}_{2}\left[{ }_{\mathrm{CP} 1}\right.$ that $\left[{ }_{\mathrm{S}}\right.$ Hillary $\mathrm{s}_{1}$ be pregnant]]]]

b. $\exists s_{2}\left[\operatorname{exist}^{\prime}\left(s t, s_{2}\right) \& \exists t\left[t<s t \& \operatorname{believe}^{\prime}\left(t, b, s_{2},{ }^{\wedge} \lambda t_{3} \lambda s_{1}\left[\operatorname{be}_{-p^{\prime} e g^{\prime}}\left(s_{1}, h\right)\right]\right)\right]\right]$ 
$s$ is a state and exist is an operator such that [[exist]] $(s)(t)=$ true iff $t$ is included in the duration of $s . s_{2}$ and $s_{1}$ are both traces of $P r e s_{2}$, because a new index emerges when tense moves outside the intensional domain. " $\wedge$ " indicates abstraction over worlds. According to the proposed truth conditions for de re attitude verbs, (4b) is true iff (a) there is a state $s_{2}$ at the ST and an acquaintance relation $R$ that relates Bill (b) uniquely to this state $s_{2}$ in $w$ at the believing time $t$, and (b) for all cognitive alternatives $\left\langle w^{\prime}, t^{\prime}, x^{\prime}\right\rangle$ of Bill in $w$ at $t$, Bill bears the relation $R$ in $w^{\prime}$ at $t^{\prime}$ uniquely to some state, which is the state of Hillary's being pregnant in $w^{\prime}$ at $t^{\prime}$. The double access reading is captured because the truth conditions require that (a) the attitude holder and the res state are acquainted at the time of the attitude $t$, i.e., the res state overlaps with the believing time $t$, and, (b) the res state exists at the ST.

In sum, the content report mismatch is explained because in the belief worlds, Hillary is pregnant at the interval that Bill attributes to the res, which is different from the res interval overlapping with ST in the actual world. The double access overlapping reading is explained by the extra requirement that the res interval denoting the ST also overlaps with the believing time in the actual world.

\subsection{Some unintuitive consequences}

The proposed analyses treat all double access overlapping readings as involving a de re interpretation. Such an interpretation truth-conditionally requires the following factual conditions:

(A) The existence of a res state in the actual world overlapping both the ST and the belief time;

(B) The existence of an acquaintance relation causally connecting the believer with the actual res state the belief is about.

Because the truth conditions for double access sentences must satisfy these two requirements, the proposals imply that when these conditions do not obtain, the sentences are false or perhaps infelicitous. However, neither of these requirements is necessary to yield an obviously true double-access interpretation. The examples below show the intuitive inadequacy of conditions (A) and (B) above.

Consider the following. Imagine a situation in which Bill sees Hillary wearing a pretty loose dress at a party that made her look pregnant. Now, the party is over, Bill is in a business trip and Hillary of course does not 
look pregnant any more, as in fact, she never was. In this context, it is perfectly fine to utter (1):

(1) Bill believed that Hillary is pregnant.

Here, Bill is only acquainted with Hillary's loose-dress state in the past and this state does not obtain in the actual world at the ST. Of course, because Bill was deceived, it follows from his belief worlds that Hillary is pregnant at an interval including the ST (some future time from Bill's perspective). However, the state the believer is acquainted with need not obtain in the actual world at the ST as required by the de re account. Consider also the following cases:

(5) Betty told little Bill that an angel is watching him. ${ }^{1}$

(6) The detective reasoned (concluded) that the murderer is still in town.

(7) After another suspicious excuse, Hillary believed that her husband is having an affair.

(8) Socrates believed that the soul is located in the stomach.

In (5)-(8), the belief worlds entail the truth of the embedded state at the ST, but the attitude holder need not intuitively be acquainted with any particular actual state that overlaps with both the attitude time and the ST. The situations in which these reports could be true require neither the existence of some state nor the acquaintance relation. This is clear in (5). For (6)-(8), one can imagine situations that led the attitude holders to make certain conclusions, but such situations are not necessarily the actual res states the attitudes are about. In (7), for example, Hillary does not seem to believe of some state or event, (e.g., the excuse) that it has the property of being the state/event of her husband having an affair. The excuse and the affair are two different things in her mind. She simply makes a conclusion from other beliefs previously acquired or from her knowledge of her husband. Similarly, Socrates may have believed the complement of (8) as a statement compatible with his system of beliefs. This belief, a belief true of all times, may have followed from others he had, without

${ }^{1}$ Note that it does not matter that Betty lies to little Bill. From the perspective of the speaker, the attribution could be true. Note also that as in the other examples, it is possible to find an interpretation or imagine a situation in which Betty is acquainted with some Bill's state. The point is that such a use of imagination is not required. The belief attribution is perfectly felicitous and meaningfull without such stories. 
requiring an acquaintance relation with any particular or generic state that also obtains at the ST.

In all these cases, intuitions suggest that the existence of an acquaintance relation and/or an actual state overlapping with both the ST and the believing time is not truth-conditionally required. Rather, the states in question may only exist de dicto-like in the belief worlds. As noted by Abusch (1997), the belief worlds entail the truth of the embedded state at the ST in the belief worlds (a future time from the perspective of the believer) but the factuality of this state is not required. This thus challenges the adequacy of the temporal de re analysis, which makes the wrong predictions (i.e., gives the wrong truth conditions) for the examples discussed.

\section{A different solution}

In this section, I follow Gennari's (1999a; 2003) account and argue that the temporal content-report mismatch of sentences such as (1) and (2) occurs because the reports of these sentences are reports of implicit or tacit attitudes rather than de re reports, i.e., the content reported differs from that actually believed but follows from it, given other assumed beliefs. Also, I argue that the double access reading directly follows from this and the semantic definition of the present tense. The speaker reports an implicit content that implies the truth of the embedded sentence at both the ST and the believing time. The choice of the present tense correlates with a report of an implicit attitude but such reports are not restricted to double access readings.

\subsection{Background assumptions}

Implicit attitude reports are characterized by Stalnaker $(1984 ; 1990 ; 1999)$ as follows (see also Harman 1973; Dennett 1982; Stich 1983; Lycan 1986). First, reports of implicit attitudes do not make a claim about the linguistic form in which beliefs are internally represented. They simply attribute some abstract content, independently of the linguistic expression used in the report. Second, this content is not necessarily under the conscious awareness of the believer. Third, the attributed content is accessible to the believer, i.e., it is not only compatible with but easily inferable from other beliefs. Later on, I will elaborate on the notion of implicit attitude. It suffices for now to note that the philosophical literature about attitudes has pointed out the need for such a notion to account for reports that 
intuitively do not seem to be reports of explicit belief, de dicto, de se or de re. Consider, for example, the following:

(9) Russell believed that Frege's ear lobe was smaller than The Big Ben.

(10) President Clinton said that the country is doing well.

(11) My wife believes that I am less than 5 meters tall.

In (9), an example given by Stalnaker, Russell presumably did not have this explicit belief but it followed from the general pragmatic knowledge attributable to him. In (10), uttered in a situation in which Clinton has given his two-hour State of the Union speech, the president actually did not utter the complement but it was implied by his speech and everything his speech presupposed. Likewise in (11), where the speaker's wife may have not explicitly entertained the attributed belief. Note that in (11), an indexical expression is present in the embedded proposition. In the accounts discussed earlier, this automatically amounts to a de re or de se belief attribution. However, (11) cannot appropriately be analyzed this way: the wife does not attribute to the res, the husband, the property of being less than 5 meters tall. She may simply believe that no human being is as tall. Neither Russell nor Clinton or the wife may have actually had these particular thoughts but they follow from other propositions in their cognitive worlds.

The existence of implicit belief reports has important implications for the treatment of indexical tenses within intensional domains. Indexical tenses appear to be interpreted de re (Ogihara 1996) due to their very nature: Indexical tenses denote times in the utterance context, therefore, this cannot be part of the believer's worlds. However, while indexical tenses undoubtedly refer to the utterance context, it is not the case that they are always interpreted de re and/or moved outside the intensional domain. In particular, if indexical tenses can occur in implicit reports, which are neither explicit de dicto nor de re reports, it is possible that indexical tenses are not always interpreted de re. Rather, they would be interpreted as denoting some attributed implicit content, as Gennari (1999a; 2003) argues. The fact that the speaker uses an indexical reference to report the believed content is no longer problematic because the report is not intended to represent an explicit belief, i.e., the way the believer would represent it or the referential expressions he/she would use. The speaker reports an implicit proposition with his/her referential expressions (perhaps, because 
of cooperation with the addressee). This proposition must be equivalent to the one implicitly believed.

In what follows, I will assume that indexical tenses receive an interpretation in situ. Also, since I will not be dealing with de re or de se reports, which require embedded structured meanings, I assume the traditional view of belief reports as a set of world time pairs with a single temporal structure. Thus, $a$ believes $Q$ at $w$ and $t$ is true iff for all $w^{\prime}$ and $t^{\prime}$ compatible with $a$ 's beliefs at $w$ and $t, Q\left(w^{\prime}\right)\left(t^{\prime}\right)=$ true. Similarly, I assume the traditional view of tenses as quantifiers. Nothing really depends on these assumptions as the proposal can be recast in any equivalent framework. Finally, the notion of local evaluation time should be understood in the traditional logical sense: the evaluation time of a quantifier tense is the time with respect to which its truth is evaluated. Thus, in independent sentences, the evaluation time of a temporal quantifier is the ST, while in embedded sentences, it is the believer's now (i.e., the attitude time in the belief worlds).

\subsection{The meaning of the present tense and the double access reading}

Let us consider how the meaning of the present tense must be defined. This is not a trivial matter because although the tense often seems to be interpreted relative to the ST, in embedded contexts, it behaves as evaluation time sensitive, i.e., it receives different interpretations depending on the attitude time. Consider, for example, that present tense, in addition to present readings such as (12), could also receive a future interpretation as in (2):

(12) Hillary is smart.

(2) Bill will believe that Hillary is pregnant.

The embedded sentence in (2) can have both a double access and a future reading, i.e., the present tense can denote any non-past interval without necessarily referring specifically to the ST. Thus, when the attitude time is in the future, the present tense supports future readings. This contrasts with situations in which the attitude time is in the past, as in present under past reports: the double access reading is the only reading available, i.e., the reference to the ST seems obligatory. These differences in the behavior in each context suggest that the tense is both indexical and evaluation time sensitive. It is indexical because its interpretation involves a 
way of determining the referent relative to the ST (hence, its present or future - i.e., non-past - readings) and it is evaluation time sensitive because the interpretation changes with the attitude time.

I follow Gennari's (1999a; 2003) account in assuming that the present tense has the same interpretation in all independent and embedded contexts, a parsimonious assumption. The meaning of the tense requires the proposition it modifies (a) to overlap with the local evaluation time and (b) not to be located before the ST. Formally, its meaning is $\lambda i \exists i^{\prime}\left[i^{\prime}\right.$ o $i \& \neg\left(i^{\prime}<\right.$ st) $\left.\& \varphi\left(i^{\prime}\right)\right]$, where $o$ means overlap with, $i$ is the evaluation time, $i^{\prime}$ is the interval at which $\varphi$ is true, and $<$ means that the interval is wholly located before the ST. This definition essentially attributes non-past truth conditions to the present tense morphology and at the same time, it expresses a relationship with evaluation times. As Klecha (2016) points out, this is a common strategy among semanticists, see, for example, Kaufmann (2005); Giannakidou (2009); Broekhuis \& Verkuyl (2014) and Altshuler (2016). In Gennari's account, this definition is motivated by its behavior in both embedded and main clauses, so that it can capture embedded interpretations such as that of (2) as well as simple references to the ST (Gennari 2003). Indeed, note that when the proposed meaning of the present tense composes with other expressions, the evaluation time $i$ can either be the ST as in independent sentences, or the believer's now as in an embedded sentence. Also, when the evaluation time is the ST, the meaning is logically equivalent to that of overlap with the ST, replicating the effect of the traditional meaning as overlapping the ST. This is shown in (12a) below, where I omit the outermost world variable and I assume that the temporal abstract resulting from the semantic composition is finally applied to the contextual ST (see Gennari 1999a; 2003). If an interval overlaps with the ST, then, it follows that it is not wholly located before the ST:

(12) Hillary is smart.

a. $\lambda i \exists i^{\prime}\left[i^{\prime}\right.$ o $i \& \neg\left(i^{\prime}<s t\right) \&$ be-smart $\left.{ }^{\prime}\left(i^{\prime}, h\right)\right](s t)=$ $\exists i^{\prime}\left[i^{\prime}\right.$ o st \& $\neg\left(i^{\prime}<s t\right)$ \& be-smart $\left.{ }^{\prime}\left(i^{\prime}, h\right)\right]=\exists i^{\prime}\left[i^{\prime}\right.$ o st \& be-smart $\left.{ }^{\prime}\left(i^{\prime}, h\right)\right]$

(2) Bill will believe that Hillary is pregnant.

$\exists i\left[i>s^{\prime} \&\right.$ believe $^{\prime}\left(i, b, \lambda i_{0} \wedge \exists i_{1}\left[i_{1}\right.\right.$ o $i_{0} \& \neg\left(i_{1}<s t\right) \&$ be-pregnant $\left.\left.\left.^{\prime}\left(i_{1}, h\right)\right]\right)\right]$

In (2), the tense denotes any non-past interval (the interval $i_{1}$ ) overlapping with the believer's now $i_{0}$. This interval can simply overlap with the believing time or extend back into the past to include the ST. Thus, both the future and the double access readings are accounted for. Whether one or the other interpretation obtains (the size of the interval in question) de- 
pends on the context and pragmatic considerations (Dowty 1986; Gennari 2003). Consider the following examples:

(13) (When John gets home), John will think that Mary is talking on the phone.

(14) (When John gets home), John will think that Mary is in the kitchen.

(15) John will announce tonight that Mary is writing a new book.

(16) Bill will say that Hillary is his wife.

The embedded interval in (13)-(16) most likely surrounds the future evaluation time. This is because progressive events such as talking on the phone or states such as being in the kitchen do not tend to go on for long periods. Unless the distance between the ST and the future time is close enough, the overlap with the ST is not pragmatically plausible. This contrasts with (15) and (16), in which the overlap with the ST is pragmatically available. Consider now the truth conditions yielded by the regular compositional semantic rules for the case of present under past sentences:

(1) Bill believed that Hillary is pregnant.

$\exists i\left[i<s t \& \operatorname{believe}^{\prime}\left(i, b, \lambda i_{1} \wedge \exists i_{2}\left[i_{2}\right.\right.\right.$ o $i_{1} \& \neg\left(i_{2}<s t\right) \&$ be-preg $\left.\left.\left.^{\prime}\left(i_{2}, h\right)\right]\right)\right]$

This says that (1) is true iff there is an interval $i$ prior to the ST at which Bill has a belief, and for all of Bill's worlds and times $\left\langle w, i_{1}\right\rangle$, accessible from $w$ and $i_{1}$, there is an interval $i_{2}$ such that (a) it overlaps with $i_{1}$, the local evaluation time (Bill's now), (b) it is not an interval before the ST, and (c) Hillary is pregnant at it. Because of the definition of the before relation, an interval $i_{2}$ that overlaps with the believing interval $i_{1}$ and is not wholly located before the ST, necessarily requires that $i_{2}$ overlaps with both the believing interval $i_{1}$ and the ST. The double access reading is thus the only possible reading for (1).

My definition of the present tense thus captures all possible readings without appealing to additional mechanisms. The definition makes the minimal assumption that the meaning of the tense is the same in all contexts and takes at face value the distribution of temporal readings in sequence of tense phenomena (see Gennari 2003). This contrasts with Ogihara's (1996) proposal, where each of the readings is explained by a different mechanism. The double access reading is accounted for by the de re mechanism discussed above, while the future reading is obtained via a tense deletion rule. This rule deletes the embedded present tense morphology, which denotes the ST, so that the embedded sentence is interpreted as 
a tenseless temporal abstract, ultimately yielding the future overlapping reading of (2) (Ogihara 1996, 123-124).

In addition to simplicity and economy considerations, other reasons also indicate that this is a sensible definition of the present tense. First, this meaning agrees in spirit with several proposals (Kamp \& Reyle 1993; Abusch 1997; Kaufmann 2005; Giannakidou 2009; Broekhuis \& Verkuyl 2014; Klecha 2016) in which the temporal perspective or meaning of present is considered to be non-past. Also, Abusch (1988) proposes a definition of present tense where the interval denoted overlaps with the evaluation time. The novelty of this definition is that the references to the ST and to the evaluation time are put together in a way that is particularly suited to account for embedded sentences, provided the notion of implicit belief advocated here.

Second, the definition proposed is not arbitrary. It is grounded on a framework that captures important cross-linguistic generalizations. As is well known, languages like Russian and Japanese allow the use of embedded present tense in situations in which English or Spanish would use embedded past tense. Under current approaches, such cases are accounted for by claiming that present tense in these languages lacks the indexical component that English has, so that it overlaps with the local evaluation time. However, this misrepresents the fact that Japanese present tense and English simple present/present progressive can also receive future readings, e.g., co-occurring with tomorrow. To explain future readings, current accounts treat the present tense as a future operator, i.e., the tense is taken as ambiguous between these two possible readings (Ogihara 1996). Under the proposed approach, the present tense is treated as a non-past tense, i.e., it specifies that the interval denoted is not before the local evaluation time (the counterpart of the English indexical clause $=\lambda i \exists i^{\prime}\left[\neg\left(i^{\prime}<i\right) \& \varphi\left(i^{\prime}\right)\right]$ ). This makes the tense an evaluation-time-sensitive non-past, consistent with the readings of (16). Whether the actual reading is present or future will depend on contextual specifications (e.g., the location of the reference time or temporally locating expression). Thus, the cross-linguistic differences are explained in terms of general semantic properties on lexical tense meanings. Indexicality and evaluation-time sensitivity are universal properties with respect to which languages can vary (see Gennari 1999a;b; 2001; 2003).

\subsection{The content-report mismatch}

Note that the truth conditions yield an interpretation of (1) in which it follows from what Bill believed at $i$, that Hillary is pregnant during an 
interval overlapping with both the believer's now and the ST. However, these truth conditions also seem to commit the believer to a belief about an interval overlapping with a future time, the ST from the perspective of the speaker. To address this issue, I argue here that such a commitment need not be assumed if the speaker's report is viewed as a report of an implicit attitude, rather than an explicit one representing Bill's literal belief.

In (1), Bill did not actually have a belief about an interval extending into the future from his past perspective, but his belief entailed that the embedded state was true in the past and would be true in the future, given speaker's assumptions normally taken for granted. The speaker attributes to Bill typical assumptions and knowledge of the world from which the implicit content reported logically follows. If Bill believed at a time before the ST that Hillary was pregnant, the speaker could infer that Bill believed that she was pregnant and would be pregnant for a while, given that Bill has rational beliefs and typical knowledge about pregnancy. Before uttering the sentence in (1), the speaker goes through an inference schematically represented as follows:

(17) a. Bill believed that Hillary was pregnant at $t$.

b. Bill's belief worlds are rational and coherent.

c. Bill believed that Hillary had a normal pregnancy.

d. Bill knew that pregnancies typically last for an interval $i$ including $t$.

e. Bill believed that $i$ includes a future time $t^{\prime}$ (the ST from the speaker's perspective).

$\rightarrow$ Bill believed that Hillary is pregnant at $i$ including $t$ and $t^{\prime}$.

From the speaker's perspective, the future time $t^{\prime}$ in Bill's worlds is the ST. ${ }^{2}$ Note that the embedded interval denoted by the present tense in (1) exists in the belief worlds, rather than in the actual world. The inference that Hillary's pregnancy obtains at a future time $t^{\prime}$ holds in the belief worlds. However, the explicit belief may only be about a past interval (premise (a)). This is what the speaker would have reported if the inference was not possible in the current common ground (see below for examples). The speaker's inference concludes the pregnancy at the ST implicit in Bill's beliefs, given the attribution of normal assumptions and typical knowledge.

2 That the speaker uses an indexical reference to refer to the relevant time is not problematic because the report is not intended to represent the way the believer would represent this time. The speaker reports an implicit proposition, which is equivalent to the proposition given in the final line of (17). 
Note that premise (c) of (17) schematically represents other premises also implicitly assumed by the speaker. For example, Bill did not think at the time of the belief that Hillary was about to give birth, or Bill did not have any reason to think that Hillary would not have a normal and full term pregnancy. These are part of normal assumptions that the speaker takes for granted in the common ground, and thus attributes to the believer. This correctly predicts that if the speaker knew that Bill thought that Hillary's situation was somewhat atypical (for example, that Hillary was sick and could lose the child), the present under past report in (1) would be infelicitous.

The notion of implicit report, traditionally acknowledged in philosophical literature, further requires the existence of a pragmatic inference, the premises of which (if any) should be taken for granted in the common ground. In particular, I propose that an implicit report such as that in (1) is felicitous, if there is an inference pragmatically attainable in the common ground that allows the speaker to infer the attributed content. This is because, by the very nature of implicit attitudes, the speaker cannot assume any proposition as part of the belief worlds. Rather, he/she may assume those propositions that are normally taken for granted, i.e., those that constitute common knowledge and default assumptions, unless the common ground explicitly denies them. This is the crucial difference that distinguishes report of implicit attitude from other types of reports and relates to Stalnaker's notion of accessibility discussed in section 3.1. The worlds that are accessible in the common ground are those presupposed by the speaker according to general conversational principles.

The existence of implicit reports other than those involving a temporal inference provides support for the claim that belief attributions can involve an inference whose premises are taken for granted in the common ground. ${ }^{3}$ In addition, the pragmatic premises or assumptions of (17) are independently motivated on other Gricean conversational principles that

${ }^{3}$ Note that the notion of implicit attitude advocated here is not the one implied by the traditional possible world approach to attitude reports. The kind of implicit attitude claimed here is conditioned to the existence of an inference on the basis of what would normally be taken for granted. To see this, compare this notion with the problem of equivalent beliefs. If $a$ believes that Phosphorus is Phosphorus, in the traditional propositional account, a must also believe that Phosphorus is Hesperus, since the two propositions are necessarily true. The traditional account may argue that in a weak sense of belief as implicit belief, such inference may hold. Although there are theories of attitudes such as that proposed by Stalnaker $(1984 ; 1987)$ that handle this puzzle within the possible world framework, this kind of inference would not follow from my notion of implicit attitude because it would not be normally assumed 
interlocutors normally assume when making and interpreting attitude reports. As several studies have pointed out (cf. McCawley 1978; Stalnaker 1981; 1987; Barwise \& Perry 1983; Farkas 1992), when the speaker makes an attitude report, he/she normally assumes that (a) attitude holders are rational beings, i.e., belief worlds tend to be not contradictory (I call this assumption the coherence principle); and (b) that the belief worlds agree with the actual world (or with the version of the actual world that the speaker presupposes) in all relevant respects except for those in which the speaker has given the hearer reasons to believe that they may differ (equal knowledge principle). The coherence principle ensures that the believers to whom one attributes beliefs are not mentally ill and are not aware of contradictions in their beliefs (if any). The equal knowledge principle guarantees that believers can be assumed to have typical knowledge about the world, knowledge that anybody would have, as the speaker has. These assumptions are clearly operative in (17). Since the believer is coherent (premise (b)), has typical knowledge about the world and makes normal assumptions about Hillary's situation as presupposed in the utterance context (premises (c) and (d)), the speaker can infer that the believer's worlds are such that they entail the persistence of a certain state. When principles of this sort are not respected, infelicitous assertions arise.

In short, this account requires the standard semantic analysis of beliefreports, according to which (1) is true iff it follows from all the worlds compatible with Bill's beliefs that Hillary is pregnant during an interval overlapping with both the believing time and the ST. This is the implicit content attributed by the believer. However, these truth conditions are only applicable when felicity conditions have been satisfied. These conditions require that the speaker's inference attributing the implicit embedded content is attainable in the common ground according to general conversational principles. The speaker is thus responsible for the use of the present tense with its corresponding semantic interpretation via his/her own pragmatic inference. What creates the intuition that the speaker misrepresents the original belief is the inference process the speaker goes through in the report, which in most cases attributes a stronger belief than the original content, given the premises added to the belief worlds.

that anybody has complete knowledge of either astronomy or all the sentences that express the same proposition. 


\section{Accounting for difficult cases}

\subsection{Discontinuous, interrupted and non-existent states}

The approach proposed in the previous section can predict why examples presupposing discontinuous states in the actual world are not acceptable. These examples have been used in the literature to support the claim that the state with which the believer is acquainted should obtain in the actual world at an interval overlapping with the believing time and the ST. Consider, for example, a case slightly different from one given by Ogihara (1996):

(18) John and Bill are looking into a room. Sue is in the room.

Bill (nearsighted): Look! Hillary is standing in the room.

John: What are you talking about? That's Sue, not Hillary.

On the following day John and Kent meet at the same location and are now looking into the same room. Sue is standing there.

John (to Kent): ${ }^{\#}$ Bill believed yesterday that Hillary is standing in the room. But that's Sue, not Hillary.

The attitude report in (18) is infelicitous. This is because under normal assumptions, an inference such as that in (17) applied to this case would not normally follow. Consider how the inference would be formulated:

(19) a. Bill believed that Hillary was in the room at $t$.

b. Bill's belief worlds are coherent.

c. Bill believed that Hillary was in a typical state of being in the room.

d. Bill knew that a state such as being in a room typically lasts for an interval $i$ including $t$.

e. *Bill believed that $i$ includes a future time $t^{\prime}$ (the ST from the speaker's perspective).

$\rightarrow$ Bill believed that Hillary is in the room at $i$ including $t$ and $t^{\prime}$.

To obtain the reported content the speaker should assume that the state in question would typically hold in the belief worlds for a period $i$ that includes the ST (premise (e)). However, this assumption does not hold because it contradicts common sense knowledge about the duration of the state. Bill likely believed that Sue would stand there for a while but not until next day. The speaker thus cannot assume that temporary states such as that of standing in a room hold for long periods without contradicting 
what the speaker him/herself presupposes and without violating the equal knowledge principle discussed earlier.

This type of pragmatic reasoning also makes the right predictions for cases in which no actual state obtains at the ST because it has been interrupted. Consider a case like (20) in which Sue leaves the room and Kent joins John and Bill a few minutes later. This is a case discussed by Ogihara, who claims that the example shows the inadequacy of truth conditions similar to those proposed here (Ogihara (op.cit., 197):

(20) John and Bill are looking into a room. Sue is in the room.

Bill (nearsighted): Look! Hillary is standing in the room.

John: What are you talking about? That's Sue, not Hillary.

Bill: I am sure that is Hillary.

Sue leaves the room. Few minutes later, Kent joins them.

John (to Kent): ${ }^{\#}$ Bill believed that Hillary is standing in the room. But that's Sue, not Hillary.

In such a situation, the present under past report in the last line of (20) is not felicitous, as the situation does not support the assumption of a premise such as (19e). The speaker cannot take for granted that the interval in which Sue is in the room in Bill's worlds includes the time in which she leaves. Being in a room could be a fairly short state, and Bill could have thought that Sue would be in the room for a few minutes. If Bill shares general world knowledge with most of us, Bill may have thought that Sue (or his representation of Sue as Hillary) would stay in the room as long as she needed, i.e., her stay was dependent on other events (e.g., on whatever she was doing in the room). Therefore, Bill's worlds are compatible with a belief in which Sue eventually leaves the room (at some unspecified future time). Thus, unless the speaker has independent reasons to assume that in Bill's worlds, Sue would be in a room for a long period of time (say, because she typically works for long periods in her office), the assumptions of $(19 \mathrm{e})$ is not guaranteed. Because no specific information is provided in (20) and the state of being in a room does not have a typical duration as in the pregnancy case, the speaker would be violating basic conversational principles such as the equal knowledge principle by attributing to Bill some arbitrary period of time outside the normal expectations compatible with the information provided. What explains these cases is the violation of pragmatic felicity conditions, not the inadequacy of the truth conditions.

In some cases of interrupted or non-existent states, the pragmatic conditions do justify the attribution of an implicit belief. According to the 
equal knowledge principle, such attributions should make available in the context that the believer does not have access to the same information the speaker presupposes. This is the case of (1), in a context where Hillary's dress deceives Bill:

\section{(1) Bill believed that Hillary is pregnant.}

In the context provided, the speaker knows that Hillary was never pregnant but can assume that she was and would be in the belief worlds since Bill was deceived. Likewise for Socrates' example (8), since given what we know about him, such a generic belief would follow from his past beliefs regardless of what happens at the ST in the actual world (or regardless of whether there is any relevant actual state). Note that these examples do not violate common sense assumptions about the duration of states as in (19) and (20). The reported belief preserves the coherence of the belief worlds, is compatible with common sense assumptions and with what is presupposed in the common ground. The report can be felicitous, although no state may obtain at the ST in the actual world. Thus, the examples of this section show that the felicity of a present under past report depends on whether a pragmatic inference can be constructed according to cooperative conversational principles. If what the speaker assumes in the belief worlds is incompatible with the presupposed context and common sense assumptions, the asserted inference is not felicitous.

\subsection{The generic/episodic contrast}

If it is correct that the speaker makes an inference that assumes common knowledge about the typical duration of states, one would expect variations in the acceptability of present under past reports depending on the degree of reliability of such an assumption. This is an issue particularly for those embedded states that may not hold between the time of the attitude and the ST as exemplified in (19). If common knowledge does not support the inference, the report should be unacceptable. In contrast, if no issue arises as to whether the embedded state can hold for the period specified, the attribution should be fine. This is indeed what we find. Note that among the stative sentences that can occur embedded under past, there are at least two classes corresponding to the distinctions between generic vs. episodic sentences (Carlson 1977; Kratzer 1989; Chierchia 1995). At the level of lexical stative verbs, this distinction corresponds to the distinction between individual level and stage level predicates. Sentences containing individual 
level predicates and generic sentences in general express permanent or typically stable properties. In contrast, sentences containing stage level predicates express temporary qualities or states.

It should become clear now why the generic/non-generic distinction has an effect on the acceptability of present under past attributions. This is so because temporary states (stage level predicates) will yield awkward attributions if they are asserted to hold for periods that are longer than what one would normally expect according to world knowledge. Consider for example:

(21) ?'Last year, Bill believed/told me that Hillary is pregnant.

(22) ?'Last week, the dean told me that Ms. Jones is sad.

(23) 'Last month, the secretary told the dean that Ms. Jones is upset with him.

Compare these sentences with the following:

(8) Socrates believed that the soul is located in the stomach.

(24) Scientists believed that human psychology starts to develop after birth.

(25) I used to believe that dogs and cats love each other.

(26) Last week, the dean told me that Ms. Jones is walking/walks to school.

Generic sentences (both habitual and with individual level predicates) are fine no matter how long ago the attitude took place. They do not require specific conditions to be acceptable when embedded under past because the original generic belief contained quantification over typical situations (the sentence is habitually true), and therefore, it logically entails that the embedded sentence is true for a period encompassing the believing time and the ST. The presence of the inference is pragmatically unquestionable and does not require extra common sense assumptions. In contrast, temporary states hold for periods that are grounded in typical knowledge so they are most likely to yield infelicitous present under past sentences if common sense assumptions are not satisfied (as in (19)). The less likely the assumption, the less felicitous the sentence, hence the various degrees of acceptability. In general, the presence of an inference more or less pragmatically grounded (including logical inferences as those unquestionably grounded) determines the felicity of present under past reports. 


\subsection{The present belief}

The acceptability of present under past belief reports seems to be affected by the beliefs the believer holds at the ST: If the common ground includes the information that the belief held in the past is no longer held at the $\mathrm{ST}$, the present under past attribution is not felicitous. Consider some examples:

(27) Bill and John are looking into a room. Sue is in the room.

Bill (nearsighted): Look! Hillary is in the room.

John: What are you talking about? That's Sue, not Hillary.

Bill: Yes, you are right. That's Sue.

One minute later, Kent joins them. John (to Kent):

\#Bill believed that Hillary is in the room.

(28) Bill knows that Hillary lives in California now.

\#However, for a while, he believed that Hillary lives in Boston and expected to call her up to go out together.

(29) Bill found out that Hillary is not pregnant.

${ }^{\#}$ However, for a while, he believed she is pregnant.

When a present belief different from the past belief is available in the common ground, belief attributions are not acceptable. Facts of this nature support a pragmatic account, because the information available in the common ground at the time of the attribution has an effect on felicity. This kind of cases are problematic for the de re account because the requirement that the state to which the believer is acquainted persists until the ST does not take care of belief changes about this state (e.g., Hillary being fat and not pregnant in (29)).

When the speaker attributes an implicit belief, his/her assumptions must be grounded in the common ground, i.e., they can be taken for granted only when they are unquestionably presupposed. If the common ground makes clear that the believer does not believe proposition $\mathrm{A}$, the speaker cannot take this proposition for granted in the belief worlds without violating basic cooperation principles: the premises necessary for the speaker's inference are true neither in the common ground (proposition A does not hold in the actual world) nor in the believer's worlds, thus violating both the equal knowledge and the coherent-worlds principles. Consider the inference in (17) again, applied to (29). Bill explicitly believed that Hillary was pregnant at the time of his belief (premise (a)), and according 
to the speaker, Bill implicitly believed that Hillary would be pregnant at some future time (the ST) in premise (e). This premise contradicts the common ground information that Bill believes that Hillary is not pregnant at the ST and attributes contradictory worlds to him. Rather than making Bill appear contradictory, the cooperative way to characterize Bill's belief is to say that he was confused.

\subsection{Other pragmatic factors}

Consider a situation such as that in (1) in which Hillary was pregnant, had the baby and got pregnant again. Bill saw Hillary a month ago but he does not know anything about Hillary's present state or Hillary's having the baby. In this situation, the report in (1), Bill believed that Hillary is pregnant is infelicitous. The de re account handles this case via the requirement that the state obtaining in the actual world overlaps with both the $\mathrm{ST}$ and the believing time. In the present account, no state is required to exist in the actual world but Bill still has a belief about one state rather than two, since the meaning of the present tense forces the embedded proposition to be true throughout the interval overlapping with the believing time and the ST. However, in a situation where the speaker knows that there were two pregnancies involved, it would be simply uncooperative to utter (1), since the speakers does not provide all the information that is relevant for the situation. This is also true for the past version of (1). For the speaker to be informative, he/she must report Bill's belief in a way that clearly characterizes Bill's beliefs against what is presupposed in the speaker's context. In the context given, the speaker actually means something like (30):

(30) Bill thought that Hillary is/was still pregnant from the first pregnancy.

Therefore, using (1) or its past version would be misleading, since it does not make clear to the hearer what Bill actually had in mind, given the actual situation.

In terms of Stalnaker's (1978) theory of assertion - and many pragmatically-inspired accounts of assertions, e.g., Roberts (2012) -, the asserted report does not satisfy the conditions for a felicitous assertion: The speaker does not distinguish between the possible worlds of the current common ground, thus making the proposition false in some worlds and true in others. An assertion that is true in all (relevant) worlds of the common ground is infelicitous. For example, (1) does not distinguish between a 
belief about the first or the second pregnancy. According to Heim (1992), a belief report such as (1) instructs one to exclude from the common ground those worlds in which Bill does not believe that Hillary is pregnant. But since in this case, Bill can have such a belief regarding one of the two states (e.g., Bill does not believe that Hillary was pregnant for the second time), the speaker's contribution is not informative and the assertion is not felicitous. This captures Gricean informativeness principle in a precise way: the assertion was not informative enough relative to the current common ground. Thus, the contrast between (30) and (1) in the context provided suggests that in addition to the common sense assumptions discussed above, other general pragmatic principles such as Gricean cooperation and informativeness principles may determine the acceptability of present under past reports.

\subsection{Summarizing felicity conditions}

Present under past reports are felicitous if the premises that allow the speaker to attribute an implicit belief are attainable in the context of the attribution, i.e., if the speaker makes the implicit attribution according to general Gricean maxims of cooperation. Sections 4.1 to 4.4 have discussed some specific principles applying to belief attributions that follow from general cooperative behavior, for example, the assumption that believers are coherent and share the speaker's knowledge of the world, unless otherwise specified (see Barwise \& Perry 1983; Stalnaker 1987). Such principles are operative in all belief attributions but are particularly at stake in present under past reports because these reports make a claim that is stronger than the claim otherwise required: The situations in which present under past reports are true include those in which past under past are true, but not vice versa. With present under past reports, the speaker commits him/herself to an inference about the believer's implicit content by invoking common ground assumptions. When these assumptions are available in the context, present under past reports are more informative, and thus, more appropriate via informativeness, than past under past reports. When these assumptions fail in a particular context, present under past reports become infelicitous, and only past under past reports are appropriate.

What are then the contextual properties that license felicitous present under past reports? First, properties of the attributed state should conform to general world knowledge and typicality expectations, in particular, the duration of the believed state and its possible future continuity relative to the believing time. This is particularly problematic for beliefs about non- 
generic temporary states, as discussed in 4.1 and 4.2. Second, coherence of the belief worlds should be preserved. This factor can make an attribution felicitous or infelicitous depending on the common ground. If the common ground contains the information that the belief reported is false in the actual world, then, the report can only be felicitous if the believer is presupposed not to have access to this information (section 4.1.). Alternatively, if the common ground makes available that the believer does not believe the attributed content anymore, the present under past report is infelicitous because it makes the belief world contradictory. In general, the belief attribution should conform to general principles of cooperation and informativeness, so that the attribution actually contributes some content relative to the worlds of the common ground (as discussed in 4.3). Contexts that violate such principles (including common-knowledge and coherence principles) do not support the premises needed to make an implicit report, and therefore, make such reports infelicitous.

To clarify the present approach, note that it is not argued that all attitude reports are implicit belief attributions. In most cases, they are not. But the presence of indexical tenses in the embedded clause are typical candidates for implicit attributions, because the attitude holder is likely not acquainted with the ST, unless he/she is present at the utterance situation. Moreover, it is not argued that de re belief attributions do not exist. Much has been said in the philosophical literature about cases of mistaken identity, which are clearly de re. The point here is that true de re beliefs are not expressed with grammatical tools that speakers have at their disposal, like tenses, person or number suffixes. If the speaker wants to attribute to someone a mistaken representation of a particular event or state of affairs, he/she would simply not use a tense to do so, but references to the eventuality in question, e.g., John thought that the wedding was a funeral. Finally, there might be differences between different attitude verbs, as pointed by Klecha (2016), which are beyond the scope of this work.

\section{Present under future}

Present under future sentences in their double access reading have similar characteristics to present under past ones. Consider, for example:

(31) The dean will say that Ms. Jones is his wife.

a. $\exists i\left[i>s t \& s^{\prime} a y^{\prime}\left(i\right.\right.$, the-dean $^{\prime}, \lambda i_{0} \wedge \exists i^{\prime}\left[i^{\prime}\right.$ o $i_{0} \& \neg\left(i^{\prime}<s t\right) \&$ be-wife $\left(i^{\prime}\right.$, jones' $\left.\left.\left.)\right]\right)\right]$ 
(32) The dean will believe that Bill's records are not good enough.

a. $\exists i\left[i>s t \&\right.$ believe $^{\prime}\left(i\right.$, the-dean ${ }^{\prime}, \lambda i_{0} \wedge \exists i^{\prime}\left[i^{\prime}\right.$ o $i_{0} \& \neg\left(i^{\prime}<s t\right) \&$ $\neg$ be-good' $\left(i^{\prime}\right.$, Bill's-records' $\left.\left.\left.)\right]\right)\right]$

Note that by the above definition of the present tense, the two temporal readings in these sentences are obtained. The condition of not being an interval prior to the ST can be satisfied in different ways. For example, (31a) is true in two possible situations: when Ms. Jones is the dean's wife at some future interval overlapping with the dean's saying time, and when Ms. Jones is currently the dean's wife and continues to be until the dean's saying time. In the first case, the event time of the present complement $i$ ' is a future interval overlapping with the future local evaluation time. In the other case, this interval is extended enough to overlap with the ST and the future local evaluation time. Whether the embedded interval overlaps with the ST will be determined by the context.

When the double access reading obtains, there is a mismatch between the content actually believed, which did not include a reference to ST, and that reported. As in the case of present under past, the speaker attributes an implicit future attitude based on an inference including common sense assumptions. The speaker attributes an attitude that will be such that, given normal assumptions, it will entail something true about the past of the attitude time (the ST), although the attitude holder may not know this at the ST. The difference with present under past reports is that what is entailed by the belief worlds looks backward instead of forward, i.e., once the believer acquires certain knowledge, his/her view of the past will change. For example, in (32), the dean will believe that Bill's records are bad at a future time $t$. But, since the dean will learn that Bill's records are generally bad at an interval $i$ including $t$, and since $i$ includes $t-1$ (the ST), it follows that the dean will believe that Bill's records are bad at an interval including $t-1$. (31) behaves similarly, except that here, since a verbal attitude is involved, the dean will not necessarily acquire a new belief, as (32) suggests, but could say what he/she already knows.

This analysis is supported by facts similar to those found with present under past reports regarding the continuity and actuality of the states involved. Assuming a context where Hillary is about to deceive Bill by wearing a loose dress, the future under past report need not require the currency of the state in question at the ST:

(33) Bill will think that Hillary is pregnant.

(34) Humans will never know whether there is life in other galaxies. 
At a future time, Bill will think that Hillary currently is and has been pregnant, given the characteristics of this state, although no state may obtain at the ST. In addition, a res state obtaining at the actual world is not required as (34) shows. Thus, the inferential approach correctly accounts for these cases.

Present under future reports are also similar to present under past ones with respect to the contrast observed between generic and episodic complements. Generic complements are usually fine independently of the time intervening between the ST and the future attribution, while the felicity of temporary states with the double access reading depends on whether the assumption that the complement state holds for the indicated period is pragmatically attainable:

(35) Next year, the dean will believe that Bill is sad.

(36) Next year, the dean will believe that the secretary is pregnant.

(37) The dean will believe that Ms. Jones is not trustworthy.

(38) The students will think that Socrates is the greatest philosopher of all times.

In the double access reading, the speaker should infer from normal pragmatic assumptions that the complement state would remain true from the attribution time backward to the ST, unless he/she has given reasons to suspend them. If such assumptions are unattainable in the common ground as in (35) and (36), for the same kinds of pragmatic reasons indicated for present under past, the double access reading will not arise. Thus, these brief considerations and the parallelisms noted with present under past attributions suggest that the general approach proposed for present under past sentences extends to the case of present under future.

\section{Future under past}

As with present tense, the future tense in embedded sentences is sensitive to the local evaluation time in a way that is constrained by its indexical reference to the ST. Consider some examples:

(39) In two days, an official will announce that the president will apologize (*tomorrow).

(40) A journalist said that the president will resign (*yesterday). 
Note that there is a contrast between future embedded under past and future embedded under future. Sensitivity to the local evaluation time only appears in the latter case, when the evaluation time is already located in the future. This suggests that future tense requires an interpretation relative to both the ST and the evaluation time if this time is later than the ST. Formally, the meaning of future is $\lambda \varphi \lambda i\left[\exists i^{\prime}\left[i^{\prime}>i \& i^{\prime}>s t \& \varphi\left(i^{\prime}\right)\right]\right]$, i.e., it denotes a time later than the local evaluation time and later than the ST. The requirement that the future time follows the evaluation time accounts for the ungrammaticality of the adverb in (39), whereas the requirement that the future time follows the ST accounts for the ungrammaticality of the adverb in (40). When the local evaluation time is located before the $\mathrm{ST}$, as in (40), or is equal to it, the first conjunct of the definition does not have any effect on the temporal interpretation, as the definition is equivalent to another one without it (for any evaluation time $t^{\prime} \leq \mathrm{ST}$, if there is a time $t>\mathrm{ST} \& t>t^{\prime}$, then $t>\mathrm{ST}$; see Gennari 2003 for details). Consider now the case of future under past in more detail:

(41) The dean believed that Mary will leave (tomorrow).

a. $\exists i_{1}\left[i_{1}<s t \&\right.$ believe $\left(i_{1}, d, \wedge \lambda i \exists i_{2}\left[i_{2}>i \& i_{2}>s t \&\right.\right.$ leave $\left.\left.\left.\left.\left(i_{2}, m\right)\right]\right)\right]\right]$

(41a) is true iff there is an interval $i_{1}$ prior to ST in which the dean believes that there is another interval $i_{2}$ later than the past attitude interval and later than the ST in which Mary leaves. As with present tense, this definition entails that the believer has a belief about the ST (the content report mismatch intuition). The believer could not have known in the past anything about a future event happening tomorrow after some future time (the ST) from his past perspective. To explain this, the general pattern of explanation proposed for embedded present tense also applies to embedded future. The fact that there may be a speaker's inference involved is clear: If the dean believed yesterday that Mary would leave (say, in two days), one can report (41) today. Although the dean refers to a time located in the future of his/her believing time (e.g., in the second day after the day of his/her belief), the content of the attitude entails that this time is also located in the future of the speaker's ST. Consider how the inference involved could be given:

(42) a. The dean believed at $t$ that at a future time $t^{\prime}>t$ Mary would leave.

b. The dean is coherent and shares the speaker's knowledge about temporal relations. 
c. The dean knew that for any time $t^{\prime \prime}$ included in the interval between his/her believing time $t$ and the future leaving time $t^{\prime}, t^{\prime}$ is later than $t^{\prime \prime}$.

$\rightarrow$ The dean believed that Mary will leave at $t^{\prime}>t^{\prime \prime}\left(t^{\prime \prime}=\right.$ the ST from the speaker's perspective).

The inference requires an implicit assumption: in the dean's belief worlds, any time $t^{\prime \prime}$ included in between the past belief time and the future leaving time will be a time $t^{\prime \prime}$ such that the leaving time is located after it. This licenses that the speaker refers to this time using an indexical tense, although the believer does not have access to the utterance time. A similar inference would apply if the speaker uses the referring expression tomorrow, where $t^{\prime}$ is this time from the speaker's perspective, $t$ is within yesterday and the dean believed that Mary would leave in two days. Note also that this inference would not follow if in (42), the dean believed that Mary would leave some time later within the same day, i.e., yesterday from the perspective of the speaker. In such a case, the speaker cannot refer to the believed leaving time with the future tense because it would not follow that the ST falls within the believing time and the leaving time, and the truth conditions of the tense would not apply. The analysis thus makes the right kind of predictions.

\section{Present under past without double access interpretations}

It appears that in some contexts, the present tense can be used to report attitudes that do not overlap with the attitude's time, but it does relates to the ST as in main clauses. Consider the following examples

(43) Peter said that the dean is meeting him at 10.

(44) Customer: I believe you have my bags.

Employee: Who said I have your bags?

Customer: The stewardess told me you have my bags.

Employee: When did she tell you that?

Customer: On the flight.

Many speakers do not accept these cases (44), where would is preferred in the embedded clause. (43) can be easily accounted for if the meaning of the progressive and aktionsart considerations are taken into account (Dowty 1979; Moens \& Steedman 1988). As predicted by the semantic 
definition of the present tense, the tense imposes an overlapping interpretation between the meeting event and the attitude's time. This is indeed the case, but what overlaps with the attitude's time is not the meeting event strictly speaking, but the preparation phase of this event, e.g., the fact that is already scheduled and it is thus "current" at the ST. As argued in Dowty (1979) and Gennari (1999b; 2003), formal semantics accounts of tenses need to allow for variations in interpretation coming from aktionsart, because these considerations are derived from the interaction of the tense and the lexical meaning of the verbs at hand.

For the case of (44), Altshuler and Schwarzschild (2013) indicate that this exchange took place at an Air Berlin baggage counter but we do not know whether the speakers were native English speakers. These authors argue that this case should be analyzed as a de re interpretation. However, this strategy brings back all the problems of de re analyses, in particular, acquaintance relationships: the stewardess need not be acquainted with any particular interval or state for (44) to be true. At the flight, the stewardess probably said that a company employee would have the bags. To make (44) a felicitous report of this intentional content, we can again appeal to the notion of implicit report: given reasonable assumptions about the stewardess' intensional worlds, the speaker can deduce that the relevant employee the stewardess was talking about is the person he is now talking to, and moreover, that he has the bags, where the reference to the ST corresponds to the future time the stewardess was talking about. Thus, the stewardess' statement at $t$ that an employee will have the bags at $t_{1}>t$, is reported relative to the ST because $t_{1}=\mathrm{ST}$ from the speaker's perspective. The stewardess was talking about and implicitly thought of a future interval that would include the ST, even if the stewardess did not think of it as such. In terms of the content-report mismatch, this case is no different from other implicit reports with indexical tenses discussed above, and it can only be uttered if the sort felicity conditions discussed above hold. Yet what makes (44) stronger than other cases discussed above is that in the truth conditions, the evaluation time of the embedded clause is no longer the attitude's time as in (1) but rather the ST, as in main independent clauses. This is consistent with the definition of present tense where $\lambda i \exists i^{\prime}\left[i^{\prime}\right.$ o $\left.i \& \neg\left(i^{\prime}<s t\right) \& \varphi\left(i^{\prime}\right)\right]$ is interpreted relative to the ST, but such an interpretation must be restricted to cases where felicity conditions obtain.

Altshuler (2016) also put forward other examples found in corpora that seem to suggest that present under past reports receive overlapping readings with the past attitude's time, rather than the ST. For example, 
I called him and he said he is on his way and will be at my place at 7pm. He never came. However, this is not acceptable for most native English speakers, and the source of this statement in social media is an Indian English speaker who is very likely to speak other languages. Such speakers are naturally predisposed to errors or transfers from their native languages. It seems therefore inadequate to abandon a definition of the present tense that works on typical cases across embedded and independent contexts to explain marginal uses. In the same way that speech errors and false starts characteristic of spoken language do not affect someone's grammatical knowledge, on-the-spot English uses in social media are not necessarily counterexamples to semantic accounts. There will always be idiosyncrasies, speech errors and non-native speakers in naturalistic linguistic corpora.

Nevertheless, there seems to be a lot of variation in the semantic judgments for tense uses. For example, Bary and Altshuler (2015) put forward several cases in which they believe present under past reports receive a purely simultaneous interpretation with the main clause, and not a double access reading. Consider an example: We're standing around sipping cokes and talking about the election. Slowly, one by one, folks are walking away from me. And then I realized that once again I'm being argumentative. Sheila is right. It turns people off. Native speakers I have consulted would much prefer to use past tense in the embedded clause, but it appears that some English speakers accept this case. One problem with obtaining judgments about tense uses from speakers is that the meaning of the sentence can be understood independently of the tense used, so informants may accept such cases, even if they would not use a present tense in such situations. This in part depends on how the judgments are obtained. One way to address this issue in a more objective way is to elicit productions from speakers in a particular context, rather than simply asking speakers whether they accept a sentence. Gennari and Macdonald (2005/2006) have taken this approach to investigate the various possible readings of quantifier scope ambiguities. Another possibility would be to investigate brain responses with EEG or reading times, where unexpected tense uses should elicit a surprise response during reading, even though the meaning of the sentence, or indeed, what the speaker is intends to say, can be understood. This approach was used in Gennari (2004) to show that past tensed stative sentences in embedded clauses preferentially receive an overlapping interpretation with the time of the main clause, because readers are surprised when they encounter a temporal adverbial indicating a non-overlapping interpretation. The fact that embedded past tense is preferentially interpreted as overlapping with the time of the main clause 
provides some indication that embedded past tense and not embedded present tense is the preferred way to indicate purely simultaneous readings with the time of the main verb. Thus, more objective measures with statistical methods are needed to determine the preferred interpretations in present under past reports.

\section{Summary and conclusions}

The present work proposes that the indexical tenses can be analyzed as occurring within the attributed propositional content, when such content constitutes inferred content, i.e., an attribution of an implicit belief (Stalnaker $1981 ; 1987 ; 1990)$. Such implicit content is not necessarily part of the belief intuitively entertained, but they are pragmatically inferred. Implicit attitudes are such that their felicity is constrained by the existence of an inference pragmatically attainable. This account preserves the traditional possible world account that belief should be treated as a relation between an individual and a proposition but constrains belief attributions via pragmatic principles. The attribution should be felicitous in the speaker's context. This was necessary because (a) current de re analyses of tenses are not empirically adequate, (b) indexical tenses in attitude contexts can generally be explained as attributions of implicit propositional beliefs that establish equivalences with the time of speech and (c)unintuitive inferences and consequences of allowing indexical expressions within intentional domains can be blocked on pragmatic grounds: no speaker in his/her right mind would attribute or infer such contents if the context does not support the necessary assumptions. This proposal does not require complex or ad-hoc semantic analyses and takes advantage of pragmatic principles already available in the language.

\section{Acknowledgements}

I am in debt to Pauline Jacobson for innumerable comments and support and to Craige Roberts for conversations that inspired this article. I also thank the audience of SALT IX for useful comments on ideas that improved this paper. 


\section{References}

Abusch, Dorit. 1991. The present under past as de re interpretation. In D. Bates (ed.) Proceedings of the Tenth West Coast Conference on Formal Linguistics. Stanford, CA: CSLI Publications. 1-12.

Abusch, Dorit. 1997. Sequence of tense and temporal de re. Linguistics and Philosophy 20. $1-50$.

Altshuler, Daniel. 2016. Events, states and times. An essay on narrative discourse in English. Warsaw \& Berlin: de Gruyter Open.

Altshuler, Daniel and Roger Schwarzschild. 2013. Moment of change, cessation implicatures and simultaneous readings. In E. Chemla, V. Homer and G. Winterstein (eds.) Proceedings of Sinn und Bedeutung 17. Paris: ENC. 45-62.

Barwise, Jon and John Perry. 1983. Situations and attitudes. Cambridge, MA: MIT Press.

Bary, Corien and Daniel Altshuler. 2015. Double access. In E. Csipak and H. Zeijlstra (eds.) Proceedings of sinn und bedeutung 19. Göttingen: LinG. 89-106.

Broekhuis, Hans and Henk Verkuyl. 2014. Binary tense and modality. Natural Language \& Linguistic Theory 32. 973-1009.

Carlson, Gregory N. 1977. A unified analysis of the English bare plural. Linguistics and Philosophy 3. 413-457.

Chierchia, Gennaro. 1995. Individual level predicates as inherent generics. In G. Carlson and F. Pelletier (eds.) The generic book. Chicago: The University of Chicago Press. $176-223$.

Comrie, Bernard. 1985. Tense. Cambridge: Cambridge University Press.

Cresswell, Max J. and Armin von Stechow. 1982. De re belief generalized. Linguistics and Philosophy 5. 503-535.

Dennett, Daniel C. 1982. Beyond belief. In A. Woodfield (ed.) Thought and object: Essays on intensionality. Oxford: Oxford University Press. 1-95.

Dowty, David R. 1979. Word meaning and Montague grammar: The semantics of verbs and times in generative syntax and in Montague's PTQ. Dordrecht: Reidel.

Dowty, David R. 1986. The effects of aspectual class on the temporal structure of discourse: semantics or pragmatics? Linguistics and Philosophy 9. 37-61.

Enç, Mürvet. 1987. Anchoring conditions for tense. Linguistic Inquiry 18. 633-658.

Farkas, Donka. 1992. Two types of world-creating predicates. In D. Brentari, G. Larson and L. MacLeod (eds.) The joy of grammar. Amsterdam \& Philadelphia: John Benjamins. $35-71$.

Gennari, Silvia and Maryellen C. MacDonald. 2005/2006. Acquisition of negation and quantification: Insights from adult production and comprehension. Language Acquisition 13. 125-168.

Gennari, Silvia P. 1999a. Embedded Present Tense and attitude reports. In T. Matthews and D. Strolovitch (eds.) Semantics and linguistic theory (SALT) IX. Ithaca, NY: CLC Publications, Cornell University. 91-108.

Gennari, Silvia P. 1999b. Tense, aktionsart and sequence of tense. In F. Corblin, C. D. Sorin and J.-M. Marandin (eds.) Empirical issues in formal syntax and semantics 2. The Hague: Thesus. 309-329. 
Gennari, Silvia P. 2001. Tense, aspect and aktionsart in Spanish and Japanese. Maryland Working Papers in Linguistics 11. 60-84.

Gennari, Silvia P. 2003. Tense meanings and temporal interpretation. Journal of Semantics 20. $35-71$.

Gennari, Silvia P. 2004. Temporal references and temporal relations in sentence comprehension. Journal of Experimental Psychology: Learning, Memory and Cognition 30. 877-890.

Giannakidou, Anastasia. 2009. The dependency of the subjunctive revisited: Temporal semantics and polarity. Lingua 119. 1883-1908.

Harman, Gilbert. 1973. Thought. Princeton, NJ: Princeton University Press.

Heim, Irene. 1992. Presupposition projection and the semantics of attitude verbs. Journal of Semantics 9. 183-221.

Kamp, Hans and Uwe Reyle. 1993. From discourse to logic. Dordrecht: Kluwer.

Kaplan, David. 1968. Quantifying in. Syntheses 19. 178-214.

Kaufmann, Stefan. 2005. Conditional truth and future reference. Journal of Semantics 22. 231-280.

Klecha, Peter. 2016. Modality and embedded temporal operators. Semantics \& Pragmatics 9. $1-55$.

Kratzer, Angelika. 1989. Stage-level and individual-level predicates. In E. Bach, A. Kratzer and B. Partee (eds.) Papers on quantification. Amherst: University of Massachusetts. $147-222$.

Lewis, David. 1979. Attitudes de dicto and de se. Philosophical Review 88. 513-543.

Lycan, William G. 1986. Tacit belief. In R. J. Bogdan (ed.) Belief: Form, content and function. Oxford: Oxford University Press. 61-82.

McCawley, James D. 1978. World creating predicates. Versus 19/20. 77-93.

Moens, Marc and Mark Steedman. 1988. Temporal ontology and temporal reference. Computational Linguistics 14. 15-29.

Ogihara, Toshiyuki. 1996. Tense, attitudes and scope. Dordrecht: Kluwer.

Quine, Willard Van Orman. 1960. Word and object. Cambridge, MA: MIT Press.

Roberts, Craige. 2012. Information structure: Towards an integrated formal theory of pragmatics. Semantics and Pragmatics 5. 1-69.

Smith, Carlota S. 1978. The syntax and interpretation of temporal expressions English. Linguistics and Philosophy 2. 43-99.

Stalnaker, Robert. 1999. Context and content. Oxford: Oxford University Press.

Stalnaker, Robert C. 1978. Assertion. In P. Cole (ed.) Syntax and semantics 9. New York: Academic Press. 315-332.

Stalnaker, Robert C. 1981. Indexical belief. Synthese 49. 129-151.

Stalnaker, Robert C. 1984. Inquiry. Cambridge, MA: MIT Press.

Stalnaker, Robert C. 1987. Semantics for belief. Philosophical Topics 15. 177-190.

Stalnaker, Robert C. 1990. Mental content and linguistic form. Philosophical Studies 58. 129-146.

Stich, Stephen. 1983. From folk psychology to cognitive science. Cambridge, MA: MIT Press. 